\title{
El control contramayoritario como marco de análisis de la influencia del nuevo constitucionalismo latinoamericano sobre la democracia
}

\author{
Countermajoritarian control as framework for the analysis of the influence \\ of the new Latin American constitutionalism upon democracy
}

\author{
FRANZ BARRIOS-SUVELZA
}

Universidad de Erfurt, Alemania

\section{Como citar/Citation}

Barrios-Suvelza, F. (2018). El control contramayoritario como marco de análisis de la influencia del nuevo constitucionalismo latinoamericano sobre la democracia. Revista Española de Ciencia Política, 47, 39-68. Doi:https://doi.org/10.21308/recp.47.02

\section{Resumen}

Tanto críticos como simpatizantes del nuevo constitucionalismo latinoamericano (NCL), que es como algunos han calificado la ola de reformas constitucionales llevadas a cabo en Venezuela, Ecuador y Bolivia entre 1999 y 2009, coinciden en que tales reformas han producido una alteración en los dispositivos de control contramayoritario en dichos países. Sin embargo, este hallazgo acusa cierta debilidad conceptual en torno a diversos aspectos como son: a) la naturaleza de los dispositivos de control contramayoritario; b) la lógica de relación de estos con la democracia; c) lo que la existencia de dichos dispositivos nos dice sobre el alcance de la democracia misma; d) la entidad dentro de la cual operan estos dispositivos y la democracia, y finalmente e) las novedades reales del NCL frente a un pasado que, desde cierta perspectiva, podría considerarse carente de un sistema desarrollado de control contramayoritario. Este artículo propone un esquema conceptual alternativo para resolver, al menos en parte, estos dilemas de orden conceptual, pero sin cuyo esclarecimiento mal podría abordarse un trabajo de carácter empírico.

Palabras clave: nuevo constitucionalismo latinoamericano, Estado de derecho, democracia, autoritarismo, populismo, movimientos sociales.

\footnotetext{
Abstract

Both critics and endorsers of the new Latin American constitutionalism (NLAC), as the wave of constitutional reforms carried out in Venezuela, Ecuador and Bolivia between 1999 and
} 
2009 is referred to, agree that these reforms have altered the countermajoritarian control devises in the above countries. However, this finding shows some conceptual flaws relating to several aspects such as: a) the nature of the countermajoritarian control devices; b) their logic of relationship with democracy; c) what the very existence of these devices reveals about the scope of democracy itself; d) the entity where these devises and democracy operate, and finally e) the actual novelty of NLAC compared to the past which, from some perspective, lacked a developed system of countermajoritarian control. This article proposes a new conceptual approach to resolve, at least partially, the above-mentioned conceptual dilemmas which need to be clarified before an empirical work could be properly tackled.

Keywords: New Latin American Constitutionalism, rule of law, democracy, authoritarianism, populism, social movements.

\section{INTRODUCCIÓN}

Pensar los cambios contemporáneos de la estatalidad latinoamericana no puede dejar de lado la irrupción del así llamado nuevo constitucionalismo latinoamericano (NCL). El concepto mismo de NCL (Viciano y Martínez, 2011) no está libre de polémica (Salazar, 2013: 54 y ss.; Ávila, 2011: 17, 75) ni hay acuerdo definitivo sobre el abanico de países que barca $^{1}$ ni hay certeza desde la perspectiva histórica de si hubo novedad real de amplio alcance como resultado de este fenómeno. Mientras algunos autores sostienen que sí hubo tal novedad (Avritzer 2017; Vidotte y Sousa, 2017; Belloso, 2015; Mota, 2017: 77), otros lo dudan (Gargarella, 2017: 216; Mayorga, 2010). A pesar de ello, hay suficientes elementos para asumir que existe un patrón de cambio constitucional peculiar. Siguiendo parte de la literatura (King, 2013; Couso, 2013; Vidotte y Sousa, 2017: 109) este artículo considera a Venezuela, Ecuador y Bolivia como los países que el NCL abarca habida cuenta de las reformas constitucionales totales que experimentaron en 1999, 2008 y 2009, respectivamente. No se puede abundar aquí sobre la multiplicidad de aspectos que este fenómeno supone (Nolte y Schilling-Vacaflor, 2012). El artículo se focaliza más bien en la llamativa expresión que, en el marco del NCL, ha asumido la clásica dicotomía entre democracia, por un lado, y fenómenos como «Estado de derecho», "control y balances» o «división del poder», por el otro. Esta dicotomía, en sus diversas manifestaciones, representa

1. Avritzer (2017: 30), por ejemplo, incluye bajo «nuevo constitucionalismo» la reconstitucionalización de 1988 en Brasil, mientras que saca a Venezuela del abanico por la deriva autoritaria del chavismo y critica a quienes incluyen solo a Bolivia y Ecuador por reducirse así demasiado el tema a la cuestión indígena. Por su parte, Wolkmer y Machado (2011: 403) detectan más bien tres ciclos del nuevo constitucionalismo, el primero conformado por las experiencias constitucionales de Brasil y Colombia en 1988 y 1991 respectivamente, el segundo representado por Venezuela en 1999 y un tercero que engloba a Ecuador y Bolivia en 2008 y 2009 respectivamente. 
una controversia permanente en las ciencias políticas (Habermas, 1994; Sejersted, 1988; Sunstein, 1988), aunque su debate no ha producido respuestas concluyentes sobre el contenido preciso de los polos comparados, ni sobre la naturaleza de su relación, ni sobre la envoltura institucional bajo la cual se articulan.

Como punto de partida se puede tomar la afirmación de los críticos al NCL de que en los países en cuestión se estaría produciendo un severo proceso de «desinstitucionalización» (Mayorga, 2010: 5), siendo una de sus víctimas el Estado de derecho (Brewer-Carías, 2009; Mayorga, 2010: 5). Lo que no se sabe es qué parte de lo que habría sido desmantelado en términos de institucionalidad es cubierto por el concepto «Estado de derecho». Una solución a esta interrogante no es posible con este concepto $\mathrm{u}$ otro de comparable singularidad (por ser muy estrecho), ni con el de «institucionalidad» (por ser muy vago). A esa dificultad se suma que el desmantelamiento de institucionalidad al que se alude suele venir conectado a una valoración de su impacto sobre la salud de la democracia en estos países. Para muchos críticos del NCL, el desmantelamiento de la institucionalidad ha implicado, automáticamente, el derrumbe de la democracia (Mayorga, 2010; Brewer-Carías, 2010).

Esta nebulosa conceptual se complica más si se suma lo que piensan sobre estos acontecimientos tanto los políticos involucrados como los teóricos pro-NCL. Los líderes de estos procesos han insistido en que cuando llegaron al poder encontraron una institucionalidad ya estropeada. Lo que a los ojos del crítico del NCL aparece como un desmantelamiento tout court de la institucionalidad, mencionando solo al pasar su deterioro previo, representa para los propulsores del NCL más bien, una tarea de reparación de una institucionalidad dañada en un pasado etiquetado como neoliberal. En Bolivia Evo Morales recordaba, por ejemplo, que antes de llegar a la Presidencia, imperaba en su país una subordinación de los órganos de la justicia al neoliberalismo, y de que estos eran corruptos y «enemigos del pueblo» ${ }^{2}$. En los académicos pro-NCL esta visión adopta un lenguaje sofisticado, como cuando se proclama que lo que el NCL ha hecho es permitir la superación del concepto convencional de Estado de derecho mediante el de «Estado de derechos» (Avila, 2011). Para los teóricos simpatizantes con el $\mathrm{NCL}^{3}$, este viraje del componente institucional lejos de enterrar lo democrático habría facilitado «recomponer» la brecha entre soberanía y Gobierno heredada del pasado mediante una diversificación de modalidades de ejercicio democrático del poder (Viciano y Martínez, 2011:21).

2. Declaración de Morales en Telesur, 20-05-2007.

3. En este artículo se hablará de autores «pro» NCL abstrayendo por el momento de los sentimientos de ratificación o frustración que, de cara al fenómeno, dichos simpatizantes hayan podido desarrollar en el curso del tiempo. No se pueden rastrear aquí con detalle estos oleajes anímicos y baste citar solo dos ejemplos paradigmáticos de esta trama intelectual. Por un lado, está la contemporizadora posición de Boaventura de Souza Santos frente a la deriva venezolana bajo Maduro (Página 12, 5-6-2017) y, por otro, la más bien clara crítica de Viciano y Martínez al respecto (El Pais, 26-5-2017). 
Para establecer un marco conceptual firme que permita comprender el impacto del NCL sobre la dicotomía democracia vs. dispositivos contramayoritarios, el artículo analiza cinco fallas conceptuales recurrentes en la posición crítica al NCL. En primer lugar, está la diversidad de términos con los que se describe lo que se habría desmantelando en términos de institucionalidad. A momentos es el concepto de «Estado de derecho", incluyendo la independencia judicial, el que parece ocupar el lugar de categoría genérica, mientras que otros prefieren hablar de fallas de «institucionalidad» y otros, con más precisión, se referirán a un deterioro de la horizontal accountability (HA), aunque tampoco faltaran quienes encapsulen todo bajo la idea de un «ataque al basamento liberal». En segundo lugar, está la presunción de que democracia debe identificarse con su variante representativa declarando como su virtud principal la capacidad de lograr consensos. En tercer lugar, la crítica al NCL parte generalmente del supuesto de que los dispositivos institucionales averiados por el NCL son un subconjunto del concepto de democracia, haciendo que el deterioro de ellos acabe arrastrando la democracia hacia una crisis terminal desde dentro de ella misma. En cuarto lugar, no queda claro cuál es la entidad dentro de la cual se produce la tensión dicotómica entre democracia vs. dispositivos contramayoritarios. Finalmente, la crítica al NCL es renuente a profundizar sobre dónde radicaría la diferencia entre el deterioro que en este campo habría traído el NCL, frente al deterioro que estos mismos dispositivos ya sufrían antes de que el NCL irrumpiera.

Por lo dicho hasta aquí, queda claro que el enfoque de este artículo se centrará en lo conceptual más que en una verificación empírica de lo que viene sucediendo en el NCL. Por conceptual se entiende, siguiendo a Munck (2010), uno de los dos dominios (el otro es el de la teorización propiamente dicha) de elaboración teórica dentro de la producción de conocimiento científico en las ciencias sociales. Este bloque teórico binario antecede al empírico, subdividido a su vez en medición y evaluación de causalidades (Munck, 2010: 2, 10). Otra opción hubiera sido entrar de lleno en la medición de indicadores de independencia judicial o Estado de derecho en los países del NCL. O se hubiera podido, por ejemplo, cuantificar el grado de "delegatividad» en la democracia de dichos países (González, 2014). Como para O’Donnell (2011:21) la HA es un factor relevante de su concepto de «democracia delegativa», mucho de lo que estos estudios empíricos miden da pautas importantes, aunque indirectas, sobre la cuestión del desmantelamiento institucional que los críticos le achacan al NCL. No es sorpresivo, pues, que Bolivia, Ecuador y Venezuela acusen severos incrementos en valores pro «delegabilidad» justo en el contexto de su transición hacia el NCL (González, 2014: 244). Sin restar mérito a esos esfuerzos vale la pena, sin embargo, detenerse por un momento y, antes de continuar con las mediciones empíricas, preguntarse si la conceptualización misma de las variables en juego está tan consolidada como se asume. Es cierto que en la ciencia política actual la formación de conceptos como tal ha sido rebajada a ser solo un "preludio" a la «investigación seria» (crítico Schedler, 2011: 370). No obstante, parece arriesgado lanzarse a una medición empírica de estos fenómenos y a la evaluación de causalidades sin haber previamente sometido a stress analítico los conceptos básicos que les conciernen (Munck, 2010: 4; Møller y Skaaning 2014: 1). 
Una segunda advertencia con relación al enfoque del presente artículo deriva del hecho de que, si bien se trabajará indagando la solidez conceptual con la que los académicos críticos al NCL han operado, lo que esta ola de cambio constitucional es, no es lo mismo a lo que los académicos piensan de ella. Sin embargo, la filosofía que informa el proceso real de transformación del Estado bajo la égida del NCL no puede entreverse sin trabajar el reflejo subjetivo que el genera en la academia que, sea por su especialización o, incluso, por su involucramiento sentimental con el NCL, se convierte en un acceso privilegiado para comprenderlo. Esto vale siempre y cuando se tenga el cuidado de no confundir proceso social con su representación subjetiva y de tener consciencia de las brechas que naturalmente quedarán entre lo que realmente pasa y lo que los observadores interpretan sobre ello. El artículo comienza con una recapitulación de ciertas premisas teóricas que la doctrina pro-NCL ha presentado en relación con el tema de análisis a fin de tener una contextualización del análisis. En la sección siguiente se abordan las cinco fallas conceptuales básicas de la crítica al NCL en relación a la dicotomía democracia vs. dispositivos contramayoritarios. En la última sección se esboza un enfoque conceptual alternativo capaz de dar cuenta del cambio de estatalidad en América Latina suscitado en el marco del NCL a la luz de su impacto sobre la dicotomía mencionada.

\section{EL ENFOQUE PRO-NCL EN LA TEMÁTICA DEMOCRACIA Y EN LA DEL DESMANTELAMIENTO DE LA INSTITUCIONALIDAD}

Para los teóricos pro-NCL, el NCL fue producto de reivindicaciones populares (Viciano y Martínez, 2011: 7) y supuso la recuperación del «constitucionalismo revolucionario" (Martínez, 2010: 31). Aunque estos autores no desconocen cierta continuidad con el constitucionalismo del pasado, en especial con aquella corriente que exigió que la constitución adquiriera un papel de marco efectivo de regulación de las relaciones políticas y jurídicas (Viciano y Martínez, 2011: 8), la preocupación central de este proceso no habría sido la dimensión jurídica de la constitución, sino la legitimidad democrática de la misma (ibid.: 7). Dentro de ese marco, estos teóricos avanzan cuatro postulados relevantes para el caso aquí tratado.

\section{Hacia una limitación legitima del poder estatal}

Los teóricos pro-NCL sostienen que el NCL «supera el concepto de constitución como mera limitadora del poder (constituido) y se incide en la definición de la constitución como fórmula donde el poder constituyente expresa su voluntad» (Viciano y Martínez, 2011: 4). Esto pone énfasis en la facilitación del ejercicio del poder, antes que en su impedimento. A esta visión le es concomitante la tesis de que como solo puede haber «un» poder en el Estado, es mejor hablar de una asignación de «funciones» que de una "división» de poderes (Martínez, 2010: 26). Ello deja intuir de 
antemano la esmirriada relevancia que tendrán dispositivos de contrapeso típicos del Estado liberal. Como lo recuerda Wolff (2008: 177), sin embargo, la relativización de los sistemas convencionales de control, no implica que para el NCL el tema mismo del control desapareciera. El punto es que quien debe ahora ser actor del control, no puede ser más una agencia no electa que ejerce un contrapeso guiada por criterios formalistas o tecnicistas. Es en este contexto que los teóricos valoran como "principal novedad» (Martínez, 2010: 27) la creación de la «función de transparencia y control social» en la Constitución ecuatoriana de 2008.

\section{Del Estado de derecho al Estado de «derechos»}

Los teóricos también toman posición en torno al «Estado de derecho». Esta toma de posición puede ser colocada analíticamente dentro de tres perspectivas. Por un lado, la toma de posición en torno al Estado de derecho puede verse como opción a favor del llamado Estado de derecho «material» frente al «formal» (Lauth y Sehring, 2009: 176) y puede tomar la forma de lo que se ha llamado un «Estado de derechos» entendido como superación del Estado de derecho convencional (Aparicio, 2008: 22; Ávila, 2011: 107 y ss.; Belloso, 2015: 43). Este último —imbuido por una tradición liberal - se habría centrado en la sujeción del poder a un ordenamiento jurídico, mientras que el «Estado de derechos» rescataría a los sujetos —individuales o colectivos- como la razón de ser del quehacer estatal (Aparicio, 2008: 22; Ávila, 2011: 136). En este contexto el uso del plural «derechos» se saluda como visualización del nuevo entramado constitucional que acaba yendo «más allá del concepto clásico de «Estado de derecho» cuya no mención se justifica en su incorporación tácita en la denominación Estado constitucional» (Viciano y Martínez, 2011: 24). Por otro lado, se puede ubicar la toma de posición en torno al Estado de derecho dentro del contexto de una crítica al Estado y al derecho modernos (Belloso, 2015: 29). Si estos dos últimos conceptos se cuestionan de raíz (Vidotte y Sousa, 2017: 99), mal podría el concepto de Estado de derecho quedar intacto. Finalmente, la toma de posición podría verse en el contexto de la pretensión de sacar la soberanía popular de la camisa de fuerza que representaría el Estado de derecho, que habría hecho las veces de una tinaja dentro de la cual lo democrático habita incómodamente constreñido (Vidotte y Sousa, 2017: 102; Belloso, 2015: 35).

\section{Regeneración de lo democrático}

Los autores pro-NCL reconocen que la constitución es un medio indispensable de regulación del quehacer político, lo cual relativiza aquella crítica que cree que en los países del NCL (Viciano y Martínez, 2011: 10) se habría pretendido llevar todo o mucho al método plebiscitario. Con todo, es claro que el NCL apuesta por reforzar la expresión directa de los ciudadanos (Wolff, 2008: 174; Vidotte y Sousa, 2017: 112; 
Grijalva, 2017: 121). En esa medida lo plebiscitario no aparece como mácula, sino como expresión de lo democrático. Si bien los teóricos se ven conectados a la tradición del "constitucionalismo liberal revolucionario»(Viciano y Martínez, 2011: 14), advierten que las introducciones de nuevas formas de participación no se hacen a costa del principio del sistema de democracia representativa (Viciano y Martínez, 2011: 21). No obstante, si bien no se pretende desmontar la democracia representativa queda claro que hay un afán real en el NCL por lograr una «regeneración» (Viciano y Martínez, 2010: 23) de lo democrático, una reposición del poder constituyente (Vidotte y Sousa, 2017: 105; Belloso 2015: 42) o un encumbramiento de la participación (Avritzer, 2017: 28; Belloso, 2015: 40). Resulta pues muy apresurado afirmar como Gargarella (2017: 211) que la persistencia de rasgos centrales del viejo patrón de organización del poder que habría estado basado en una muy limitada noción de democracia, prácticamente desmiente la novedad atribuida al NCL. Los teóricos pro-NCL ven en el NCL un triunfo de la democracia «material» sobre la «formal» (Viciano y Martínez, 2011: 15). Viciano y Martínez $(2011: 16,21)$ concluyen que el «rasgo más reconocible» de la "nueva institucionalidad» del NCL es la participación que legitima al ejercicio de gobierno. Esta conclusión explica también por qué este enfoque no pueda escapar al dilema que representa defender que el poder constituyente se deba imponer al poder constituido (Viciano y Martínez, 2011: 17), habida cuenta que no solo en el poder constituyente sino en el constituido se implican modalidades de participación. El que en este contexto los autores pro-NCL destaquen el papel de las cortes constitucionales es solo a primera vista algo contradictorio con su visión democratizante pues una corte constitucional, más que instancia de contrapoder frente a lo que el pueblo en su versión de poder constituido pueda aspirar, se concibe como garante de lo que el pueblo como constituyente dejó establecido (Martínez, 2010: 27, 9; Bellloso, 2015: 42). Además, proponen la «incorporación de elementos de legitimidad democrática de la corte constitucional» (Martínez, 2010: 29) o finalmente suponen que hasta un juez puede ser democrático en la medida en que sepa dar participación en igualdad de condiciones a las partes durante su labor interpretativa (Grijalva, 2017: 124). La complejidad de esta temática se revela en la contradicción que surge debido a que se trata de un proceso que, por un lado, genera una expansión de derechos y, por otro, refuerza concomitantemente el poder judicial que no es precisamente la expresión de la mayoría (Belloso, 2015: 47) y que no pocas veces acaba dominado por un Ejecutivo que si bien se presenta como transformador, reproduciría un estilo viejo de predominio frente a las otras ramas del Estado (Grijalva, 2017: 133).

La expansión del rol del pueblo en este esquema se deja también notar cuando se lo postula como el «primer fiscalizador» (Martínez, 2010: 27). Se supone que la nueva "función» de «supervisión ciudadana permanente sobre toda actividad de gobierno" logra la superación de la democracia representativa en aras de una «democracia social y participativa» (ibid.: 28). No por casualidad se considera al "Consejo Nacional de Participación Ciudadana» regulado en la nueva Constitución del Ecuador como el "principal organismo" (Grijalva, 2012: 33) dentro de la nueva función de control. Ahora bien, el que en el caso ecuatoriano se haya incluido a la contraloría o a las 
superintendencias bajo la nueva «función de control» no significa necesariamente que tales entidades se liberen del nuevo paradigma de una "ciudadanía controlando». A pesar de los cascajos organizacionales que puedan quedar en la forma de oficinas de una contraloría o de una agencia de regulación, no parece alterarse el hecho de que se produce un desmantelamiento del modelo convencional del «control técnico» (Wolff, 2008: 176).

\section{Indicaciones sobre el tándem democracia vs. institucionalidad}

Finalmente, se cuenta con indicaciones para entrever la posición de estos teóricos en cuanto a la relación entre democracia e institucionalidad. Ella se refleja cuando sostienen que no se parte de que «soberanía popular y el principio democrático actúen exclusivamente en el marco del orden jurídico, pero sí que también extienden sus efectos en el mundo de lo ordenado" (Viciano y Martínez, 2011:2). Esta hipótesis es reveladora pues al suscribir la naturalidad de un decisionismo mayoritario fuera del orden jurídico - aunque probablemente aún dentro del Estado- se desconecta la definición de democracia de su usual mezcla con otros temas de configuración estatal como el Estado de derecho. Es en este contexto de una «corrección» de la «institucionalidad» propia al NCL donde estos teóricos enaltecen la superación de la clásica «división tripartita» de poderes estatales. La consideran una de las tantas osificaciones de la tradición constitucional que no merecería — como sí lo merecen el principio de democracia o soberanía (Martínez, 2010: 19)— gozar de inmutabilidad. La idea de la división tripartita de los poderes del Estado para ellos no solo carece del peso e inmutabilidad que el tema democrático sí merece, sino que su superación se concibe como parte de una estrategia que permite conseguir «el avance democrático de las sociedades» (Martínez, 2010: 21). Se observa, pues, que el rediseño constitucional referido a la institucionalidad, dirigido a poner en jaque al Estado de derecho, a la división de poderes o a otros mecanismos emparentados, gira en torno a cómo, a costa de ellos, se pueda potenciar la democracia. Se trata de reemplazar mecanismos técnico-independientes — que se desmerecen por estar desconectados de la voluntad popular - por controles del poder asentados en el pueblo (ibid:: 24). El pueblo lograría rebasar así su rol convencionalmente reducido a su participación en procesos electorales regulares.

\section{LA CRÍTICA AL NCL EN LA TEMÁTICA DEMOCRACIA VS. INSTITUCIONALIDAD}

En contraposición a la visión recién sintetizada, se halla la academia que más severamente ha criticado al NCL por su efecto desmantelador de la institucionalidad del Estado y que ha unido este dato al derrumbe de la democracia (Levitsky y Loxton, 2013). El análisis crítico al NCL no se agota en esta versión radical. Hay análisis del NCL que, sin dejar la crítica, han sido más cautos en sus diagnósticos sobre el alcance 
de la destrucción de la institucionalidad (Cameron, 2014; Wolff, 2013) y su impacto sobre el devenir de la democracia en estos tres países ${ }^{4}$. En el presente artículo la atención se dirigirá a la versión radical de crítica al NCL. La ventaja de hacerlo así es que ella deja percibir, más rápidamente, las insuficiencias conceptuales que momentáneamente afectan tanto el análisis crítico del NCL, cuanto aquel de su impacto sobre la estatalidad latinoamericana en relación con la dicotomía democracia vs. institucionalidad. Esto no implica que el aparato conceptual de los teóricos pro-NCL recapitulado arriba no esté afectado por inconsistencias conceptuales. Sin embargo, es la academia crítica a la NCL la que dedica más atención a la imbricación entre desmontaje institucional y caída de democracia, algo que también interesa en este artículo.

\section{La inestabilidad conceptual para entender lo que se viene desmantelando en institucionalidad}

Un problema central de la crítica al NCL es que no hay acuerdo para compactar conceptualmente lo que se estaría desmantelando institucionalmente. Unos hablan de que con el NCL se habría dado un «asalto» (Mejía, 2011: 145) a «las instituciones liberales» (Salazar, 2013: 69), mientras otros destacan que se habría producido un deterioro de la HA (Madrid et al., 2010: 142), de la división de poderes (Couso, 2013: 10), de los «equilibrios institucionales» (Montúfar, 2010: 36) o, más específicamente, de la independencia judicial (Couso, 2013: 1), por no mencionar los reclamos sobre un ataque a las libertades fundamentales (Salazar, 2013: 81) y los derechos humanos (Mayorga, 2010: 37). Hay algo en lo que estos críticos parecen converger y es que se habría producido un desmantelamiento de un conjunto de dispositivos de efecto contramayoritario típicos del Estado surgido dentro de lo que O’Donnell llamara el «cuadrante noroccidental» (O’Donnell, 2001:30). Esta intuición compartida, sin embargo, carece de suficiente estabilidad conceptual que se traduce, entre otras cosas, en su incapacidad para agregar apropiadamente la diversidad de dispositivos contramayoritarios que habrían sido dañados por el NCL. Sin desconocer las sutiles diferencias que existen entre las ideas de Estado de derecho y rule of law (Grote, 1999), la sensación de inestabilidad conceptual alrededor del concepto de Estado derecho se ratifica con la afirmación de Møller y Skaaning (2014: 7) de que, en comparación con el concepto de democracia, sería mayor la "confusión conceptual» reinante respecto del concepto de rule of law. Dejando por un momento de lado la evidente inestabilidad conceptual anotada, y conscientes de que las mediciones empíricas de independencia judicial, Estado de derecho o rule of law son susceptibles de justificadas críticas (ver Møller y Skaaning, 2014), en el gráfico 1 se refleja en buena medida la línea reflexiva de los

4. Para un análisis comparativo sobre la cuestión del régimen político imperante en los países del NCL específicamente dedicado a los enfoques de Levitsky y Loxton (2013), por un lado, y Cameron (2014), por el otro, véase Barrios-Suvelza (2017). 
críticos al NCL. Su alerta sobre al desmantelamiento institucional que aducen vino de la mano del NCL parece condensarse en el ranking global de ubicación de los países para la variable rule of law calculado por el TCdata360 (bases de datos armada por el grupo «Práctica global macroeconomía, comercio e inversión» del Banco Mundial) ${ }^{5}$ para el periodo 1996 y 2016. Nótese no solo los valores deprimidos de la variable rule of law para Bolivia, Ecuador y Venezuela en comparación con el valor que aparece en el caso de Chile, sino también la convergencia de los tres países bajo análisis y la tendencia a la baja de dichos valores en relación con los tiempos en los que se produjeron las reformas constitucionales analizadas.

GrÁfico I.

Comparación del imperio de LA Ley (RULE OF LAW) ENTRE LOS PAÍSES DEL NCL

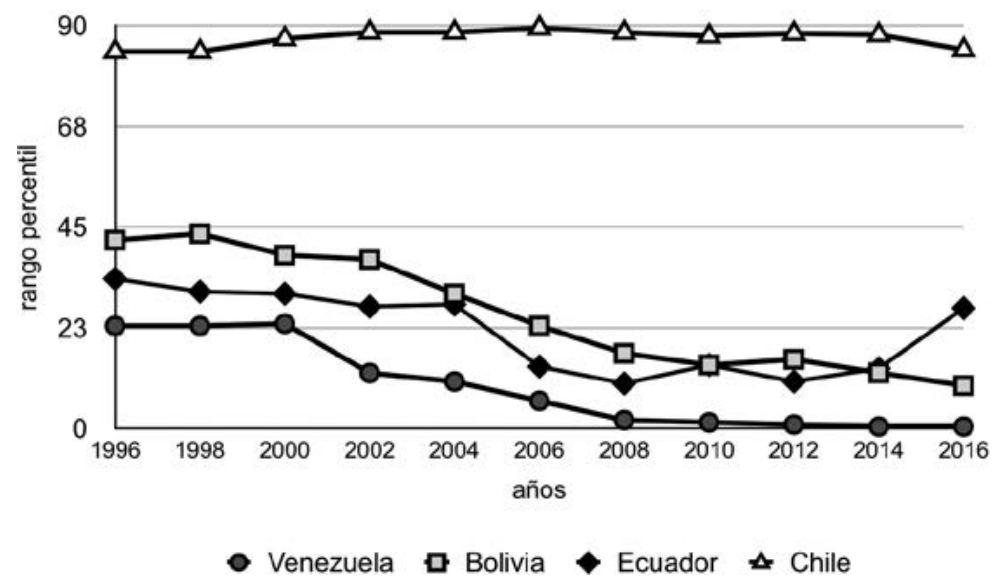

Fuente: TCdata360.

Un concepto sesgado de democracia y sus consecuencias analiticas para analizar el régimen

Al problema de la inestabilidad conceptual referido se añade el que los críticos del NCL parten de la premisa de que la democracia se agota en la forma representativa, lo cual deja aparecer técnicas como el plebiscito o el referéndum como aberrantes (Mayorga, 2010: 12, 14). Adicionalmente, se da por sentado que un Ejecutivo fuerte es por naturaleza contraproducente para la democracia. Más aún: se añade que lo democrático se define, entre otras cosas, por la capacidad de diálogo que deberían tener los gobernantes de turno con la oposición (Montúfar, 2010: 39; Mayorga, 2010: 39), lo

5. Visitado el 10/04/2018 en https://tcdata360.worldbank.org/indicators/hf5cdd4dc?country= DEU\&indicator=373\&viz=line_chart\&years=1996,2016. 
cual desplaza al factor de imposición de la voluntad mayoritaria como criterio nuclear para definir democracia. Sobre estas bases, los críticos han determinado que el régimen emergente en los países del NCL ha dejado el ámbito democrático aunque no hay consenso entre ellos en torno a cuál sería el subtipo específico de régimen no democrático que prevalecería.

Mayorga (2010: 36) descarta que la consecuencia sea el de una «democracia delegativa», o el de una "semidemocracia» o incluso el de un "autoritarismo competitivo». Según Mayorga, no parecería ser lo primero porque quien defiende la idea de lo delegativo sigue partiendo de la premisa de que, a pesar de que lo delegativo implica predominio del Ejecutivo y desactivación del control horizontal, se trataría aún de una modalidad de democracia. Esta hipótesis es para Mayorga insostenible para el caso de los países del NCL pues en ellos se habrían averiado las instituciones democráticas más allá del umbral admisible (ibid.: 37). Tampoco le parece satisfactorio el clasificador de "semidemocracia» ya que en los países del NCL el núcleo electoral estaría tan averiado como para que el término democracia haga aún sentido. Finalmente, tampoco le convence calificar como autoritarismo competitivo al régimen emergente, aunque reconoce que este sería el clasificador más pertinente. El autoritarismo competitivo supondría que las arenas de contestación al poder aún tienen sentido, lo que según Mayorga ha dejado de ser cierto para los países del NCL. Convencido de las limitaciones de estas tipologías en curso, Mayorga propone describir estos regímenes como «dictatoriales» (ibid.: 38). Esta calificación ruda no implicaría desconocer la existencia de procesos electorales periódicos que nutren a los dictadores populistas de una forma de legitimación que no deja de tener efectos reales. Sería esto lo que explicaría por qué estos regímenes no sean totalitarios (ibid.: 39).

\section{La suposición de un tándem orgánicamente inseparable entre democracia e institucionalidad}

Adicionalmente, la crítica al NCL suele partir de un contexto más general de pérdida de lo que en los noventa habría sido un consenso central: el que la democracia no sería pensable sin límites constitucionales, sin separación de poderes o sin una judicatura realmente independiente (Couso, 2013). A esta afirmación subyace un enfoque que vincula el destino de la democracia con lo que esté sucediendo con variables como «Estado de derecho» o «separación de poderes». De ahí la convicción usual de estos críticos de que es a raíz de la liquidación de estos dispositivos por lo que habrían surgido en estos países regímenes autoritarios plenos (Mayorga, 2010: 38). Según este enfoque una de las dimensiones (la democracia) no puede existir sin la otra (el Estado de derecho); si una cae, arrastra consigo a la otra. Esta interpenetración de la articulación entre democracia e institucionalidad puede darse tanto se conciba esta última como subconjunto de la democracia (que es lo más común), como cuanto se considere que ambas dimensiones no son partes la una de la otra aunque sea impensable que puedan sobrevivir separadamente. 


\section{La evaporización del Estado como probable envoltura de la tensión democracia vs. institucionalidad}

En cuanto a la entidad dentro del cual se desarrollaría la relación entre democracia, por un lado, y Estado de derecho más dispositivos afines, por otro, queda claro que si los dispositivos contramayoritarios son declarados como componentes de la democracia, la envoltura no es otra que la democracia misma ${ }^{6}$. Esto desplaza al Estado como la envoltura. Esta dilución del Estado como envoltura en favor de poner a la democracia como lo genérico, no supone que los críticos del NCL anulen el Estado como variable de análisis. Como antecedente del surgimiento del NCL se ha postulado que la democracia se desarrolló menos de lo que lo hizo el Estado tras la transición democrática (Mayorga, 2010: 9). Por lo visto, a este enfoque le tiene sin cuidado el que se compare Estado y democracia, como si fueran dos objetos de una misma escala, o como si se relacionaran como lo hacen las «condiciones generales» de algo frente a un fenómeno específico relacionado con ellas. Como Estado de derecho o división del poder suelen colocarse dentro del concepto de democracia y no dentro del Estado como envoltorio, lo que queda de Estado es básicamente una máquina de generación de orden público. La doctrina crítica del NCL trabaja pues con un concepto de Estado mutilado y esfumado.

\section{La novedad que implicaría el NCL en torno al tándem democracia-institucionalidad}

Según algunos de estos autores críticos varios preceptos que los propulsores del NCL declaran como innovadores, serían programas ya conocidos de otras tradiciones constitucionales del pasado. Salazar ha advertido, por ejemplo, la convergencia que tienen varios supuestos fundamentales del NCL tanto con el jacobinismo como el "constitucionalismo popular» del periodo fundacional norteamericano. Ambas tradiciones estarían ancladas en la desconfianza frente al control contramayoritario (Salazar, 2013: 69-70). Si algo de original habría que atribuirle al NCL en este contexto, sería simplemente el contenido idiosincrático especifico que asumen esas tradiciones cuando se las constitucionaliza en los diferentes países del NCL. Otros autores son más escépticos sobre que el NCL comporte algún tipo de novedad (Gargarella, 2017). Para Mayorga (2010: 13), por ejemplo, se trataría simplemente de ya conocidos patrones de populismo de corte estatista y basados en la trilogía líder-pueblo-Estado. Además, el NCL se sustentaría en una visión también conocida de democracia concebida como encarnación de la voluntad y unidad del pueblo (ibid.: 13). Si hubiera algo realmente nuevo, podría ser sustentable solo desde dos ópticas. Primero desde

6. La inestabilidad conceptual puede también alcanzar un resultado inverso, aunque igualmente deleznable: que sea la democracia la que acabe siendo un componente más del rule of law que es entonces lo que acaba convirtiéndose en el envoltorio genérico dando lugar al democratic rule of law (Møller y Skanning, 2014: 25). 
aquella que advierte tanto las procedencias ideológicas sui generis que caracterizan al NCL, como el indigenismo en el caso boliviano, y la decisión de recurrir a la plebe como fuente de legitimación relativizándose así el papel que jugaran los sindicatos clásicos obreros y la clase media como soportes clásicos del populismo (Mayorga, 2010: 13). La segunda óptica llamaría la atención sobre la «radicalidad en la estrategia de desmontaje de la democracia representativa" típica del NCL al relanzar la democracia "participativa» en contraste con un concepto de democracia constitucional. En este contexto sería novedosa la utilización perversa que se habría hecho de los mecanismos que la misma democracia representativa ofrece para acabar disolviéndola desde dentro (ibid.: 14).

\section{POTENCIALES SOLUCIONES A LAS DEFICIENCIAS CONCEPTUALES DE LA CRÍTICA DURA AL NCL}

Se esbozan a continuación pautas para una estabilización conceptual que supere las cinco deficiencias conceptuales de los críticos (radicales) del NCL en lo que concierne a la dicotomía entre democracia y Estado de derecho, división de poderes, etc.

\section{Hacia un subsistema estatal refractado tanto frente a lo democrático como a lo político}

El NCL ha implicado efectivamente una afectación de la «institucionalidad» en los países en cuestión. Tanto la corriente pro como la crítica ratifican este hallazgo. El problema es que no se cuenta con un concepto apto para agregar lo que, en términos de institucionalidad, está siendo afectado. Una salida insatisfactoria es elevar el concepto de rule of law a concepto-marco y en la tarea de determinar sus componentes, acabar declarando incluso la variable «democracia" como componente del rule of law (así Møller y Skaaning, 2014: 28). Aquí se propone un camino inverso: se parte de que rule of law más bien reclama un concepto aglutinador que incorpore fenómenos con los que está emparentado. En la literatura se presentan otros conceptos que podrían servir como referentes suficientemente neutros (algo que la idea de lo «liberal» como adjetivo de la institucionalidad afectada no cumple) y suficientemente amplios (cosa que conceptos aisladamente tomados como «Estado de derecho» tampoco cumplen) para resolver este dilema. De entre estos se destacan en este artículo tres: uno es el concepto de horizontal accountability (HA) propuesto por O’Donnell (2003); otro es el que se conoce como non-majoritarian institutions (Thatcher y Sweet, 2002; Majone, 1994), y el tercero es el de la llamada "dificultad contramayoritaria» (Bickel, 1986). Estas opciones, con todo lo útiles que son, tienen sus problemas ${ }^{7}$. Hay que recordar,

7. Por razones de espacio, se opta por la selección de estos tres enfoques, dejando por el momento de lado otros tantos accesos alternativos como el de la «neutralidad estatal» de C. Schmitt 
para comenzar, que la variante HA en su versión de «balance» incluye al Legislativo en sus interacciones con la rama del Ejecutivo (O’Donnell, 2003: 44). Esto no permite avanzar porque el punto que interesa no es si un Legislativo limita a un Ejecutivo, pues en tal caso se trataría de pugnas entre ramas del dominio político. Esto desfigura el propósito de una crítica al desmantelamiento de la institucionalidad pensada en función del rol de entidades como una contraloría independiente o del efecto del Estado de derecho. Una opción sería tomar del mismo O’Donnell la distinción que hiciera entre HA de balance frente a la «asignada» (ibid.: 45). En ese caso se resolvería el problema que conlleva meter al análisis el juego de balance entre ramas políticas y se focalizaría en el papel de agencias especializadas en sancionar actos ilícitos mediante mecanismos independientes. La HA «asignada", sin embargo, también falla como solución pues dado que se asienta sobre el control de legalidad, no permite abarcar una entidad como un banco central independiente cuya función normal no es sancionar actos por razones de ilicitud. Además, la HA tampoco ofrece una solución apropiada para ubicar en este contexto al sistema de servicio civil profesional.

La otra opción es la de las non-majoritarian institutions (NMI), que sí permite abarcar un banco central independiente y con mayor razón — dado que es el fuerte de este enfoque - a las agencias de regulación sectorial. El problema es que con este enfoque no es posible abordar ni el Estado de derecho — que no es una «entidad de regulación»— ni el servicio civil — que no es una agencia propiamente dicha- Además, las NMI se conciben como resultado de meras técnicas de delegación administrativa y en relación con la regulación del mercado (Thatcher, 2005: 2-3). En cuanto a la tercera opción, referida a la idea de la "dificultad contramayoritaria", se presentan otros problemas, además de aquel que cuestiona si en países como los latinoamericanos donde el poder judicial es débil frente a las otras ramas, tiene sentido del todo plantearse la temática de dificultad contramayoritaria (Grijalva, 2017: 122). Para comenzar, no está claro en qué medida los representantes del electorado aplican realmente la voluntad de la mayoría. El concepto de contramayoría no deja percibir la escisión inevitable entre demos y elite de gobierno (Easton, 1990: 107; Quiroga, 2011: 37). Más aún: es posible que sea nada menos que un juez constitucional quien, al tumbar una ley del Parlamento, sea quien reponga lo que el electorado originalmente pretendía. En ese caso, ¿cuán pertinente es calificar esta decisión judicial como counter-majoritarian?

En tercer lugar, la idea de lo contramayoritario como concepto depende del hecho electivo. Sin embargo, ¿cómo evaluar la situación en la que un juez constitucional es directamente electo, como fue el caso de Bolivia de acuerdo con lo que dispone la nueva Constitución refundacional, si este juez al día siguiente de su elección popular se sujeta

(1996); el de la «especialización funcional» de B. Ackerman (2000); el del «ascenso de los no electos» F. Vibert (2007); el de la "visión de legitimidad vía imparcialidad» de Rosanvallon (2008), o el de la dicotomía «acceso vs. ejercicio al poder» de Mazzuca (2010), por mencionar algunos de comparable relevancia. 
estrictamente a la lógica que se espera de un juez independiente? ${ }^{8}{ }$ No nos dice esto que haber elegido directamente a una autoridad pública por el pueblo no es garantía de que este mantenga su naturaleza majoritarian que se supone deriva de la elección popular? En cuarto lugar, el concepto de la dificultad contramayoritaria está calibrado más para atender el papel del Judicial y no deja pautas claras para ubicar otros mecanismos como el de ser la función pública profesional del Estado. Finalmente, en la idea de lo contramayoritario yace un dilema de fondo aún más crucial y menos percibido, a saber, el de suponer — como se hace comúnmente- que determinados mecanismos del Estado se enfrentan a «lo mayoritario» tomado como una masa indiferenciada. Se podría argumentar, sin embargo, que lo que determinados mecanismos estatales de tipo técnico o neutro tienen enfrente, si bien es algo unificado, ese algo que no es reflejado convenientemente por la idea de «lo mayoritario». Lo que tienen enfrente se revela más bien como algo constituido por dos dimensiones: lo democrático propiamente dicho, por un lado, y como uno de sus momentos intrínsecos, lo político en sentido de la élite que realmente gobierna, por el otro. Sobre el papel crucial de esta idea de un paquete binario - que contiene lo democrático, por un lado y lo político en sentido estricto, por el otro- como aquello que se contrapone a lo contramayoritario, volveremos en seguida.

\section{La búsqueda de un concepto agregador de lo que se ha desmantelado en institucionalidad}

A la luz de las insuficiencias anotadas en los tres enfoques seleccionados, urge repensar de raíz el edificio categorial en juego. Ello pasa por un ejercicio de agregación de los dispositivos dispersos («Estado de derecho», "división de poderes», o "estado constitutional») que parecen compartir un eje común. Llegados a este punto es inevitable elegir un término que refleje esta estrategia de agregación conceptual de manera aprehensible. Como la ciencia política no ha tenido mucho interés en un ejercicio semejante, mal podría haberse desarrollado un concepto que viabilizara ese propósito. Introducir un nuevo término no deja de tener riesgos (Gering, 1999). Sin embargo, la novedad de la empresa conceptual pretendida parece justificarlo. Concretamente se introduce aquí el concepto de subsistema estatal ataráxico como el agregador de los dispositivos que, sobre la base de una lógica peculiar, generan un efecto de contrapeso a lo democrático-político en el Estado9 . Para comprender este subsistema es útil expli-

8. Obviamente, en Bolivia los jueces constitucionales electos no dieron muestras de independencia como lo revela su decisión sobre la reelección de Morales (Barrios-Suvelza, 2017). Para un análisis general de los problemas de independencia judicial en Bolivia véase Castagnola y Pérez-Liñán (2011).

9. No se pueden aquí detallar las razones de haber optado por el término «ataraxia», que proviene de la tradición epicúrea, estoica y escéptica de la filosofía griega. Tampoco hay lugar para explicar por qué es un mejor término que "apatía», que en un contexto similar introdujera Elster (1979: 89). Baste mencionar que permite simplificar la comunicación de la idea de áreas dentro del Estado que operan bajo una lógica que se opone a acciones estatales regidas por vectores 
car tanto su lógica íntima de operación como su composición interna. En el marco de este artículo, solo es posible esbozar rasgos mínimos de ambas partes. En cuanto a la lógica se trata de agrupar dentro de este subsistema todos aquellos dispositivos estatales cuyas decisiones o acciones son comandadas por los principios de lo racional-formal como fueron definidos por Weber (Weber, 2005: 507; Carolan, 2009) y por la indiferencia político-moral (Kramer, 2007: 143). En cuanto a la composición, son tres las dimensiones de este subsistema estatal: la institucional, la funcional y la infraestructural. La dimensión institucional está conformada básicamente por: a) el Estado de derecho, que no debe confundirse con el derecho estatal como medio de coerción (Wolff, 1998); b) el constitucionalismo, que es la modalidad que asume hoy aquella forma de restricción que Bobbio (1986: 173) llamara sub leges para denotar la presión de normas ubicadas en la cúspide del ordenamiento y que en el medioevo tomara su fuerza de parámetros incluso jusnaturalistas, y c) los mecanismos estatales de luxación premeditada de los flujos de poder estatal cuya expresión clásica la trae el enrevesado juego de contrapesos de poder de corte madisoniano (Brodocz, 2007: 38 y ss.) y que se conoce usualmente como dispositivo de "checks and balances». Entonces, Estado de derecho, constitucionalismo, y «checks and balances» son tres aspectos autocontenidos que forman parte, cada uno por su lado, de la dimensión institucional de la ataraxia estatal ${ }^{10}$.

En la dimensión funcional se distinguen la variedad de tareas que determinados dispositivos estatales despliegan, buscando cumplir objetivos específicos de contrapeso ataráxico. Se cuentan aquí el llamado control de constitucionalidad, el control de cuentas, y otras tantas capacidades que no deben confundirse con otras tantas expresiones organizativas que las operativizan y que suelen ser lo primero que se ve. Así, a la función de regulación sectorial le corresponden organizativamente una variedad de reguladoras sectoriales, o a la función de regulación de política monetaria le corresponden las tareas de un banco central, por no mencionar entidades técnicas como un centro nacional de estadísticas o comisiones temáticamente especializadas como un ombudsman para cumplir otro tipo de funciones. Finalmente, en la dimensión infraestructural está toda la administración entendida como infraestructura técnica de ejecución de decisiones políticas, incluida su dimensión personal de un servicio civil meritocrático. Esta dimensión infraestructural se difunde de forma ubiquitaria por todo el entramado organizacional del Estado, generando áreas técnicas incluso dentro

de claro contenido material, por derroteros de transformación de la realidad según visiones de mundo específicas, sin olvidar la variable de la pasión generalmente implícita en este contexto. Sobre los diversos sentidos del término «ataraxia» desde la perspectiva de la filosofía clásica véase, por ejemplo, Bett (2015), Held (2007) y Striker (1990).

10. Møller y Skaning (2014: 18) toman un camino diametralmente opuesto y poco convincente pues proponen que además de constitucionalismo, se considere la idea de los «checks and balances» como otra manifestación más del fenómeno sub leges, para añadir luego que tanto constitucionalismo como «checks and balances» (que además declaran cómo sinónimo del concepto de HA) serían a su vez manifestaciones del rule of law. 
de la rama legislativa o, viendo la dimensión vertical de división del poder, dentro del ámbito subnacional mediante eventuales órganos independientes de control de cuentas a nivel municipal. Sobre esta base podemos precisar una de las tesis centrales de este artículo: con el NCL no se ha afectado solo el «Estado de derecho» o la «división de poderes», sino el subsistema ataráxico del Estado como tal y en sus tres dimensiones.

Para hablar de un desmantelamiento de ataraxia, se debe haber producido un quebrantamiento efectivo y decisivo de dispositivos que se hallan real y efectivamente sujetos a una lógica de carácter formal-racional y de indiferencia político-moral. Esto es importante aclararlo, pues nada impide que en los países del NCL siga operando la parafernalia organizacional de cortes y agencias reguladoras. No obstante, ello deja de ser indicador de ataraxia si dichos organismos están subordinados al poder político o a lo democrático por la razón que fuera e independientemente de los méritos o deméritos que ello implicara. En efecto, como se adelantó líneas arriba en la crítica al enfoque de la dificultad contramayoritaria, una de las cuestiones que definen al nuevo concepto de ataraxia y que lo alejan de conceptos alternativos es que implica una refracción de determinadas esferas del Estado, no solo frente a lo que comúnmente se llama la política (Carolan, 2009) o lo político-partidario, sino incluso frente al «ordenamiento democrático» (Hesse, 1999: 230). Esto contiene suficiente potencial para irritar a más de un observador, dado el predominio actual (Koselleck, 1995: 118) que lo democrático hoy ostenta al asumirse como el alfa y omega del orden estatal moderno, contemporáneo y futuro. Así las cosas, el dilema del constitucionalismo latinoamericano no es tanto o no solo por qué la rama ejecutiva acabó tendencialmente reforzada, distorsionando el modelo madisoniano de control y balances como sugiere Gargarella (2017: 218), sino por qué lo ataráxico como subsistema estatal está estructuralmente subdesarrollado frente al subsistema democracia y su dimensión de lo político en sentido estricto. Para poder ver este dilema queda claro que hay que superar el esquema clásico de la división de poder horizontal, incapaz de dejar entrever el momento ataráxico que, por así decirlo, se difunde de manera «diagonal» o ubicua dentro del tejido estatal.

\section{Hacia una recomprensión de la democracia como subsistema estatal y como contenido}

Contra la tendencia de los críticos del NCL de elevar la democracia como la envoltura mayor, la alternativa es dejar la democracia como un subsistema dentro de algo mayor (veremos en un momento cuál es esta envoltura mayor). Más aún: en cuanto tal, el subsistema «democracia» se ancla en una misma jerarquía que el subsistema ataráxico recién descrito. Si bien ambos a su vez se articulan en esa misma escala con otros tantos subsistemas comparables (piénsese en el llamado «Estado social»), interesa por el momento abundar en el par democracia-ataraxia.

Pues bien, si el status sistémico de lo democrático es el de ser un subsistema de algo, cabe ahora precisar alrededor de qué asunto se forja tal subsistema. Resulta que democracia es una de las tantas opciones que las sociedades humanas toman para 
dirimir el asunto de «quien» gobierna, no de «cómo» se hace (Lauth, 2004: 151). Democracia es aquella variante de régimen en el cual el demos influye institucional y decisivamente sobre las políticas de gobierno. Esta definición de democracia, focalizada así en su esencia, no tiene por qué mencionar de entrada al acto electoral. Primero porque este es solo un medio para perseguir un fin, a saber, el de que la voluntad mayoritaria influya decisivamente en las políticas de gobierno. En segundo lugar porque el demos puede influir mediante referéndums y plebiscitos durante el periodo interelectoral sobre políticas sin alterar los cargos políticos procedentes de las elecciones. Ahora bien, es evidente que este núcleo definicional es insuficiente para connotar apropiadamente democracia si no se añaden lo que O'Donnell (2001: 16) llamara condiciones «circundantes» del proceso electoral, especialmente las referidas a las libertades políticas. Este núcleo y sus condiciones circundantes conforman pues el paquete que determina si hay o no democracia, pero no debe olvidarse que alrededor de este paquete hay además variables requeridas para una definición completa de democracia, como aquella referida a la distancia entre la promesa electoral y las prácticas de gobierno. Fallas aquí podrán no ser determinantes para saber si hay o no democracia, pero revelan la dimensión de la calidad de la democracia que ratifica nuevamente, y a su modo, que el acto electoral es algo relativo.

Existen dos asuntos en esta definición de democracia que deben ser subrayados de cara a los teóricos pro-NCL y aquellos críticos moderados que han destacado la contribución que, en términos de participación, el NCL habría traído. Se trata, por un lado, de precisar el alcance del factor "pueblo» en la definición de democracia, y por el otro de clarificar el tipo de incidencia que se espera de ese factor sobre las políticas de gobierno. Es obvio que el tema de lo que se entiende por "pueblo» en este contexto es un tema de debate interminable (Sartori, 1995: 41 y ss.). Para este artículo es suficiente anotar lo siguiente. En el enfoque propuesto de democracia como subsistema se supone al pueblo como una categoría jurídica construida sobre la base de la igualdad de la totalidad de los ciudadanos.

Por otro lado, se trata de un actor que debe ser capaz de impactar realmente sobre la política pública. Siguiendo a Unger (2008: 26) en este punto, democracia supone que los procesos de inclusión ciudadana impliquen que el destinatario del mandato del demos está conminado a reaccionar, mientras que en otras formas de participación ciudadana, muchas de ellas basadas en el ejercicio de derechos fundamentales del individuo, el sistema las puede escuchar, pero no necesariamente implementar (Unger, 2008: 30). Por tanto, grupos humanos, por muy colectivos que sean, si comportan un carácter parcial o están alentados por intereses específicos o corporativos, no cumplen las exigencias para pasar por demos (Unger, 2008: 30) por muy encomiable que sea su activismo, incluso político, y por muy elevado que sea su valor en aras de mayor inclusión ciudadana en los asuntos públicos, pero cuyas preferencias no alcanzan necesariamente a vincular preceptivamente a las autoridades electas. De manera análoga se ha criticado los límites que supone haber dado derechos políticos sin haber afectado la lógica de procesos de gobierno que se mantienen distanciados de la ciudadanía (Gargarella, 2017: 234). 
Cabe finalmente alertar sobre dos aspectos que este enfoque de democracia no incorpora (Mainwaring et al., 2007: 128). Por un lado, no se considera parte de su definición si el Gobierno es eficaz o no, corrupto o no (Huntington, 1991: 10), "verticalista» o no. Por otro lado, tampoco se integran dentro del radio definitorio de democracia los dispositivos ataráxicos recién descritos. Esto último nos lleva al tercer aspecto de la relación entre subsistemas.

\section{Hacia una recomprensión de la relación democracia y ataraxia}

La hipótesis central es que, salvo un detalle que se explicará en seguida, la ataraxia no es un criterio cuya ausencia permitiría abrir un subtipo de democracia «disminuido», ni es ella necesaria para que exista la democracia, ni es su existencia garantía de que la democracia no pueda finalmente quebrarse, sin perjuicio de que el sistema completo de instancias independientes se mantenga. En cuanto a lo primero, se entiende si se descarta la democracia como algo que contiene variables que, como sería el caso de las ataráxicas, no hacen a su núcleo definicional. O’Donnell nos dejó en este punto con un razonamiento algo ambiguo. Primero tuvo el tino de dudar si la HA debía convertirse en uno de los componentes definitorios de la «democracia política» (O’Donnell, 2001: 32), pero cuando le tocó abundar sobre su concepto de democracia delegativa, asumió más bien la HA —que en su variante "asignada» es parte de nuestro concepto ataráxico - como un factor que acababa siendo algo interno a la democracia (O’Donnell, 2011: 21, 22). No sorprende, pues, que luego, por la vía de la técnica de subtipos «disminuidos» (Collier y Levitsky, 1997: 435), algunos autores formalizaran la HA como parte del concepto de democracia (Cameron, 2014: 8). Con ello, indefectiblemente, se pasó a considerar una falla de la $\mathrm{HA}$, no como una amenaza que viene desde un subsistema distinto al de la democracia, sino como algo que afecta a la democracia desde dentro pudiendo sustentar así un tipo de democracia «defectuosa».

Si bien es cierto que la democracia no implica negación absoluta de la idea misma de límites, pues ella no puede violar sus propias condiciones de reproducción como subsistema, ella es, por principio, reacia a límites de la naturaleza que contiene la HA de tipo "asignada». Más exactamente, es reacia a todo el subsistema ataráxico del Estado, supuesto que en este se hubiese optado por tener este subsistema. La indisposición de la democracia frente a HA no es algo que aparezca recién con la democracia delegativa como a momentos O'Donnell (2011: 21) lo da a entender, sino que se produce de entrada con la democracia tout court. Esto es lógico, pues según el propio O’Donnell (2003: 45) la HA trata de sancionar actos de agencias estatales que incurren en transgresiones o corrupción, ambos de naturaleza ilícita. Esto no concierne al núcleo definitorio de democracia, a saber: que el pueblo pueda decir algo en la hechura de decisiones estatales que acatará (Munck, 2007: 31). Un país sin determinadas instancias ataráxicas podrá eventualmente ser más corrupto o carecer de un sistema óptimo para enderezar invasiones entre ámbitos de actuación estatal, pero de ahí no se deduce necesariamente (Huntington, 1991: 10) que no tuviera democracia o que esta se hallara indefectiblemente averiada. 
La segunda hipótesis de que la democracia no requiere de los dispositivos ataráxicos impone, como se anticipó líneas arriba, una cautela. Su validez no excluye que algunos dispositivos específicos, como una corte electoral independiente, sí sean indispensables para que un régimen democrático exista. Sin embargo, eso no arrastra que todo un sistema completo de agencias similarmente independientes exista. Esto es evidente para agencias de regulación sectorial o una Oficina General de Auditoria del Estado, aunque puede ser menos claro en el caso de una corte constitucional debido a que la protección de la lógica de reproducción procedimental del régimen democrático puede acabar ventilándose en la jurisdicción constitucional. Pero como esto es contingente no se altera la tesis de que la democracia para existir no requiere de la presencia del subsistema ataraxia como paquete completo. En tercer lugar, la existencia de ataraxia tampoco puede garantizar por sí sola que la democracia no se quiebre, ya que la elite del poder puede distorsionar el campo de juego político usando medidas no justiciables, como Levitsky y Way (2010: 6) lo recuerdan.

En síntesis, esta lógica de conexión sui generis entre los subsistemas democracia y ataraxia se basa en la premisa de subsistemas que son autocontenidos sin estar del todo desconectados gracias a interfaces que, sin embargo, no dejan de ser puntuales. Estos vínculos representan de por sí un entramado tal de modalidades que su tratamiento sería imposible abordarlo aquí. Piénsese solo en las posibles «invasiones» al campo político-democrático que una corte constitucional hace cuando anula leyes, o piénsese en un vínculo en dirección inversa, cuando los políticos deciden pasar la regulación monetaria a un banco central asentado en el mundo ataráxico, sin olvidar la ya mencionada irrenunciabilidad para la democracia de una corte electoral independiente. No obstante, ambos subsistemas se reproducen siguiendo sus propias lógicas, y el que uno de ellos falle no justifica etiquetar el otro por causa de esta ausencia o falla.

La cuestión de un esquema de modalidades de interrelación entre subsistemas fue tempranamente formalizado por determinados enfoques de la teoría de sistemas (Easton, 1990; Maturana, 2002), pero también está implícito en la propuesta de "principios estructurales del Estado» (Staatsstrukturprinzipien), desarrollada por la doctrina de derecho constitucional alemán. En efecto, la idea de la ataraxia entendida como algo que no es un componente del subsistema democracia, sino como algo que representa otro subsistema de peso equivalente al del subsistema democracia y a otros comparables (como lo federal por ejemplo) que operan dentro de un mismo sistema a semejante escala estructural, converge con la idea de la doctrina constitucional alemana de que el Estado alemán está asentado en los principios de democracia, Estado social y así sucesivamente, todos con efecto equivalente de estructuración del Estado (Stern, 1984; Heun, 2012; Maurer, 2010). Esta idea guarda también parecido con la que propusiera Munck (2007:35) sobre la coexistencia de diversos «valores políticos», además del democrático, mencionando como uno de estos otros valores, justamente, al Estado de derecho. Esta última imagen converge con lo que aquí se propone con la salvedad que preferimos hablar de subsistemas y no de valores y sobre todo que, como acabamos de ver, el Estado de derecho es solo uno entre varios elementos emparentados entre sí y que por ello se dejan incluir en un concepto más agregado, generalmente invisibilizado por el análisis hasta hoy. 


\section{Recuperar al Estado como la envoltura mayor}

Según el enfoque presentado aquí, el Estado es lo que constituye la envoltura dentro de la cual los subsistemas democracia y ataraxia se interconectan. Considerar al Estado como la envoltura no es hoy obvio habida cuenta de que se lo ha venido desahuciando como actor (Deitelhoff y Steffek, 2009). Pero una vez aceptado que el Estado es el sistema de referencia, surge inmediatamente la cuestión de las modalidades de relación entre este sistema y sus partes. Este aspecto encierra más de un problema analítico. Un ejemplo de ello es cuando Levitsky y Loxton (2013) en sus análisis sobre el autoritarismo competitivo en Bolivia toman la fragilidad del Estado por fragilidad de uno de sus subsistemas. Siguiendo esta premisa, uno podría argüir que cuando Evo Morales asumió el poder el 2006 en Bolivia, lo hizo en medio de un Estado histórica y endémicamente débil institucionalmente. Sin embargo, ¿puede uno colegir de aquí, necesariamente, que la democracia como régimen haya estado tanto o más averiada que el Estado? Negar esta posibilidad es a primera vista contraintuitivo, pues ¡cómo podría la parte (el subsistema régimen democrático) ser menos frágil que el todo (el sistema «Estado»)? Pese aello, concebir un desarrollo desigual de instancias dentro del Estado parece un enfoque más realista y provechoso como en otro contexto, y con otro referente como totalidad analítica, lo sugiriera Poulantzas (1968) en su clásico análisis del Estado capitalista. En cuanto a la relación que democracia y ataraxia como subsistemas establecen con el Estado en tanto componentes de este, debe decirse que ellos se vinculan al Estado como partes al todo en una lógica de jerarquía sui genéris, dado que se basaría en el principio que los teóricos de sistemas han llamado de "anidamiento" de una escala inferior dentro de una superior, sin que esta última haga las veces de principal frente a la escala de menor rango (Easton 1990: 270). Los subsistemas democracia y ataraxia son, por lo demás, estructuralmente equivalentes entre sí, independientemente de que las constituciones, como efecto de decisiones de diseño constitucional y convicción política, den más énfasis a uno que a otro.

\section{¿Dónde queda la supuesta novedad que trajo consigo el NCL?}

Resta abordar cuánta novedad trajo el NCL respecto de la problemática democracia/ataraxia. Si por novedad hay que entender que el NCL ha establecido un «balance» entre lo liberal y la democracia representativa (Wolff, 2010: 407), por un lado, y los elementos de una concepción "posliberal» de democracia por el otro, es discutible, pues si ha habido tal balance no ha sido uno trabado necesariamente de forma convencida por los ostentadores del poder, lo que conlleva un rasgo de no autenticidad que se suma a los eventuales problemas de haber dejado en un mismo texto constitucional, contenidos simplemente «acumulados» y no «sintetizados», como Gargarella (2017: 230) advierte. Hay autores (Mota, 2017: 91) que además consideran que más que una suerte de simbiosis simétrica entre lo liberal previo y lo alcanzado en el NCL, lo que 
ha habido es una atenuación de lo liberal que queda, sin embargo, como el eje central de estos ordenamientos constitucionales. Podría tratarse, pues, de una relación asimétrica si el sistema representativo ha quedado como la base y las áreas de novedad institucional representaran solo satélites complementarios que, por lo demás, deben testificar que realmente poseen rasgos genuinamente no liberales. En el caso boliviano esto solo tiene visos de probarse mediante las autonomías indígenas (Barrios-Suvelza, 2012; Wolff, 2013), la presencia indígena acrecentada en órganos estatales o una jurisdicción indígena. Se trata, empero, de casos de una puntualidad, marginalidad o especialización que aconsejan cautela para sobre dicha base sustentar una novedad de estatalidad de amplio alcance como la que el mismo término NCL pretende, más allá del legítimo simbolismo que acompaña tal presunción.

En el debate sobre la novedad del NCL aparece tarde o temprano otro dilema: lo que aquí se llama ataraxia y los autores suelen abordar aisladamente como Estado de derecho o un judicial independiente, tampoco funcionó bien en el periodo pre-NCL (Wolff, 2008: 176; Mayorga, 2010: 10). Desde una perspectiva más histórica, Gargarella (2017: 218) sostiene que a más tardar desde mediados del siglo XIX, durante la fase "fundacional» del constitucionalismo latinoamericano, se sella una modalidad de pesos y contrapesos de entrada desbalanceada y que quedará así hasta el presente. Si esa aseveración es cierta, ¿dónde radicaría entonces la novedad del NCL respecto a ser la causa del deterioro institucional? Elucidar la novedad en el NCL es una tarea de investigación futura, pero se puede anticipar que, a diferencia del pasado, el desmantelamiento de lo ataráxico esta vez no se ha dado (tanto) por efecto de un Estado que siempre fue débil, o por mera lógica de una democracia delegativa en la que el caudillo busca neutralizar la HA en una táctica situacional de cálculo de poder. En el caso del NCL, el desmantelamiento de la ataraxia se ha hecho, por primera vez, por principio.

¿Qué significa "por principio»? Recordemos que se ha propuesto la ataraxia como un subsistema dentro del Estado que se contrapone a la democracia y también a lo político en sentido restringido, o sea, entendiendo por lo último la esfera de decisiones de la élite que realmente gobierna. El NCL no concibe este tipo de contrapesos compatible con su apuesta por una democracia como la concibe. Mientras que la ataraxia alimenta su identidad sobre la base de una legitimación que no proviene del pueblo, en la visión del NCL es el pueblo lo que debe ahora asumir no solo la guía de las políticas, sino todo el control del ejercicio del poder. En ese esquema la ataraxia es un estorbo para la visión global del Estado que alberga el NCL. Ese estorbo, sin embargo, no se puede explicar más o solamente por lo que esas instancias pudieran irritar en términos de poner en riesgo la reproducción fría o prebendal de los ostentadores del poder. En otras palabras, incluso aunque la persecución de jueces independientes no beneficiara a la acumulación de poder en manos del príncipe, o la eliminación de una contraloría independiente no lograra facilitar el uso de prebendas del aparato estatal en manos de la clase política, el desmantelamiento de la ataraxia seguiría teniendo sentido para los propulsores del NCL por el valor intrinseco que dicho desmantelamiento tiene como visión alternativa del mundo. Esto no debe, empero, llevar a creer que los operadores políticos del NCL carecieran de capacidad táctica para percibir oportunistamente cuándo y qué 
instituciones proteger y cuáles no. Su forma de operar revela que para ellos hay componentes de la institucionalidad previa que no merecen su atención. Sin embargo, han sabido mostrar benevolencia transitoria, cuando les ha convenido, por otras dimensiones de «institucionalidad» como aquellas referidas a las exigencias procedimentales requeridas por el subsistema democracia para su propia reproducción.

\section{CONCLUSIONES}

Se ha partido del postulado de que el NCL ha implicado una alteración del Estado de derecho, de la división de poderes o de la independencia judicial. Tanto quienes apoyan como quienes critican esta característica del NCL, señalan el impacto de estos cambios sobre la democracia. Sin embargo, se ha constatado que el diagnóstico sobre el desmantelamiento de la «institucionalidad» se realiza sobre un aparato conceptual inestable. Por ello se propone agrupar todo lo que el NCL desmantela en términos de «institucionalidad» bajo el concepto del «subsistema estatal ataráxico». Esto significa que es inherente a la identidad del NCL deshacerse de todos aquellos dispositivos que, por razones de racionalismo-formal y sobre la base de una indiferencia político-moral, pudieran generar un efecto de limitación al poder, tanto frente a lo democrático como frente a su dimensión de lo político en sentido estricto. Hecha esta clarificación, se añade que un subsistema ataráxico - bajo el supuesto que una sociedad ha decidido adoptarlo - no es parte de la democracia, sino un subsistema del Estado, como también lo es la democracia. En su calidad de subsistemas, tanto democracia como ataraxia, son autocontenidos; es decir, producen el grueso de sus variables de reproducción sin depender de los otros subsistemas, aunque sin por ello excluir intercambios puntuales entre subsistemas. Por tanto, el desmantelamiento de lo ataráxico, en principio, no tiene por qué conllevar el colapso de la democracia, ni su ausencia o debilidad ser justificación para la adjetivación de la democracia como algo disminuido en calidad. Y tampoco la existencia de tales dispositivos es una garantía que evite que, bajo determinadas circunstancias, la democracia colapse de todos modos.

Tanto la clarificación de lo que el NCL desmantela, como las implicaciones de esto para la democracia, son relevantes para evaluar el desarrollo de la estatalidad contemporánea en América Latina. El esquema sugerido aquí precisa el status de subsistemas dentro del Estado, y a la vez de aclarar el contenido intrínseco de cada uno de ellos, insiste en atender las lógicas de articulación entre estos subsistemas, y entre ellos y el sistema que los envuelve. Al mismo tiempo, incita a precisar el alcance conceptual de Estado, que no puede reducirse a ser un aparato de coerción. Además, permite no olvidar que, si bien es útil comparar un componente de la ataraxia como los pesos y contrapesos con una rama ejecutiva especialmente fuerte, el no entender que pertenecen a diferentes escalas dentro del sistema puede distorsionar el análisis. También puede que no sea ya tan decisivo saber por qué la rama ejecutiva ha sido demasiado fuerte en la historia de América Latina, anulando así los potenciales beneficios de pesos y contrapesos (Gargarella, 2017: 229), sino por qué la ataraxia fue en general 
más débil que el subsistema democrático y su dimensión inherente de lo político en sentido estricto.

A la luz del esquema propuesto en este artículo se pueden formular juicios más cautelosos sobre la calidad democrática del NCL sin descartar su colapso, aunque siguiendo pautas menos apresuradas y menos sesgadas de evaluación sobre la naturaleza de la forma de Estado prevaleciente en los países del NCL. Finalmente, se ha sugerido que si algún sentido tiene hablar de una novedad que hubiera venido aparejada a la ola del NCL en relación con los principios estructurantes del Estado, como son lo democrático o lo ataráxico, ella radicaría en que, esta vez, el desmantelamiento de lo ataráxico se produjo por principio. No se trata, por tanto, de negar totalmente su novedad (Gargarella, 2017: 222), sino de discutir a qué escala ella realmente se ha producido o en qué dimensiones - eventualmente menos jerárquicas pero no por ello menos efectivas — ha operado. Esta cuestión pone sobre la mesa dos temas de agenda futura. Primero, el tema de la discrepancia potencial entre bien común y voluntad mayoritaria, en la medida en que la existencia de un subsistema ataráxico óptimo puede ser una de las fuentes de un bien común entendido como una situación de beneficio a la sociedad que vas más allá de las lógicas democráticas y políticas. Estas últimas tienen su razón de ser por otras causas plausibles pero no necesariamente por la de ser fuentes seguras o indefectibles del bien común. En segundo lugar, se debe discutir cuál es el sentido que aún tiene la fórmula de que en un Estado democrático "todo» el poder estatal emana del pueblo si, por lo visto, existen determinadas áreas del Estado que de antemano no están y probablemente no tenga sentido que estén bajo el influjo de lo democrático y lo político-partidario.

\section{AGRADECIMIENTOS}

El autor agradece a los evaluadores anónimos sus sugerencias y a Mariam Hamouda su apoyo editorial.

\section{Referencias}

Ackerman, Bruce. 2000. "The new separation of powers», Harvard Law Review, 113 (3): 633-729. Disponible en: https://doi.org/10.2307/1342286.

Aparicio, Marco. 2008. «Derechos: enunciación y principios de aplicación», en R. Ávila et al. (coords.), Desafios constitucionales: la constitución ecuatoriana del 2008 en perspectiva. Quito: Ministerio de Justicia y Derechos Humanos.

Ávila Santamaría, Ramiro. 2011. El neoconstitucionalismo transformador: el estado y el derecho en la Constitución de 2008. Quito: Ediciones Abya-Yala.

Avritzer, Leonardo. 2017. «O novo constitucionalismo latino-americano: uma abordagem política», en L. Avritzer et al. (coords.), O constitucionalismo democrático latino-americano em debate: Soberania, separaçâo de poderes e sistema de direitos. Belo Horizonte: Autêntica Editora. 
Barrios-Suvelza, Franz Xavier. 2012. «The Bolivian invention: plurinationality and indigenous people within an unusual composite state structure», en F. Requejo y M. Caminal (coords.), Federalism, Plurinationality and Democratic Constitutionalism. Nueva York: Routledge.

Barrios-Suvelza, Franz Xavier. 2017. «QQué tipo de régimen político impera en los países del Nuevo Constitucionalismo Latinoamericano? Indicaciones desde el caso boliviano", Revista Latinoamericana de Politica Comparada, 12: 71-101.

Belloso, Nuria. 2015. «El neoconstitucionalismo y el nuevo constitucionalismo latinoamericano: ¿dos corrientes llamadas a entenderse?», Cuadernos Electrónicos de Filosofía del Derecho, 32: 21-53.

Bett, Richard. 2015. "What's so special about Ataraxia?»,en la conferencia Philosophy in Assos (Turkey). The Concept of Ataraxia in Stoicism, Epicureanism and Scepticism.

Bickel, Alexander M. 1986. The least dangerous branch: the Supreme Court at the bar of politics. New Haven: Yale University Press.

Bobbio, Norberto. 1986. El futuro de la democracia. México DF: Fondo de Cultura Económica.

Brewer-Carías, Allan R. 2009. «La demolición del Estado de derecho y la destrucción de la democracia en Venezuela (1999-2009)», en J. Reynoso Nunez, H. Sanchez de la Barquera y Arroyo (coords.), La democracia en su contexto. Estudios en homenaje a Dieter Nohlen en su septuagésimo aniversario. Mexico DF: Instituto de Investigaciones Jurídicas.

Brewer-Carías, Allan R. 2010. Dismantling democracy in Venezuela. The Chávez authoritarian experiment. Cambridge: Cambridge University Press. Disponible en: https://doi.org/10.1017/CBO9780511762062.

Brodocz, André. 2007. «Von der Vertical Accountability zur Horizontal Accountability. Montesquieu, die Federalists und die Transformation der Gewaltenteilung», en S. Kropp y H. J. Lauth (coords.), Gewaltenteilung und Demokratie: Konzepte und Probleme der "horizontal accountability" im interregionalen Vergleich. Baden-Baden: Nomos. Disponible en: https://doi.org/10.5771/9783845204482-28.

Cameron, Maxwell. 2014. The myth of competitive authoritarianism in the Andes. Disponible en: https://bit.ly/2IHZQHQ.

Carolan, Eoin. 2009. The new separation of powers: a theory for the modern state. Oxford; Nueva York: Oxford University Press. Disponible en: https://doi.org/10.1093/ acprof:oso/9780199568673.001.0001.

Castagnola, Andrea y Aníbal Pérez-Liñán. 2011. «Bolivia. The rise (and fall) of judicial review», en G. Helmke y J. Ríos-Figueroa (coords.), Courts in Latin America. Cambridge: Cambridge University Press.

Collier, David y Steven Levitsky. 1997. «Democracy with adjectives: Conceptual innovation in comparative research", World Politics, 49: 430-451. Disponible en: https://doi.org/10.1353/wp.1997.0009.

Couso, J. (2013). Las democracias radicales y el nuevo constitucionalismo latinoamericano. Disponible en: https://bit.ly/2IHZQHQ . 
Deitelhoff, Nicole y Jens Steffek. 2009. «Einleitung: Staatlichkeit ohne Staat?», en Was bleibt vom Staat?: Demokratie, Recht und Verfassung im globalen Zeitalter. Frankfurt: Campus Verlag.

Easton, David. 1990. The analysis of political structure. Nueva York: Routledge.

Elster, Jon. 1979. Ulysses and the sirens. Cambridge: Cambridge University Press.

Gargarella, Roberto. 2017. «The «New» Latin American Constitutionalism-Old wine in new skins», en A. Bogdandy et al. (coords.), Transformative constitutionalism in Latin America. The emergence of a new ius commune. Corby: Oxford University Press.

Gerring, John. 1999. «What makes a concept good? A critical framework for understanding concept formation in the social sciences», Polity, 31 (3): 357-393. Disponible en: https://doi.org/10.2307/3235246.

González, Lucas. 2014. «Unpacking delegative democracy- Digging into the empirical content of a rich theoretical concept», en D. Brinks et al. (coords.), Reflections on uneven democracies-The legacy of Guillermo O'Donnell. Baltimore: John Hopkins University Press.

Grijalva, Agustín. 2012. Constitucionalismo en Ecuador. Quito: Corte Constitucional del Ecuador para el Período de Transición, Centro de Estudios y Difusión del Derecho Constitucional.

Grijalva, Agustín. 2017. «Novo constitucionalismo, ativismo e independência judicial», en L. Avritzer et al. (coords.), O constitucionalismo democrático latino-americano em debate: Soberania, separação de poderes e sistema de direitos. Belo Horizonte: Autêntica Editora.

Grote, Rainer. 1999. «Rule of Law, Rechtsstaat und Etat de Droit», en C. Starck (coord.), Constitutionalism, universalism and democracy: a comparative analysis. The German contributions to the fifth world congress of the International Association of Constitutional Law. Baden-Baden: Nomos.

Habermas, Jürgen. 1994. "Über den internen Zusammenhang von Rechtsstaat und Demokratie», en U. Preuß y E.-W. Böckenförde (coords.), Zum Begriff der Verfassung: die Ordnung des Politischen. Frankfurt am Main: Fischer-Taschenbuch Verlag.

Held, Katharina. 2007. Hedone und Ataraxia bei Epikur. Paderborn: Mentis.

Hesse, Konrad. 1999. Grundzüge des Verfassungsrechts der Bundesrepublik Deutschland. Heidelberg: Müller.

Heun, Werner. 2012. Die Verfassungsordnung der Bundesrepublik Deutschland. Tübingen: Mohr Siebeck.

Huntington, Samuel P. 1991. The third wave: democratization in the late twentieth century. Norman: University of Oklahoma Press.

King, Phoebe. 2013. "Neo-Boliviarian constitutional design", en D. Galligan y M. Versteeg (coords.), Social and political foundations of constitutions. New York: Cambridge University Press. Disponible en: https://doi.org/10.1017/ CBO9780511619014. 
Koselleck, Reinhart. 1995. "Begriffsgeschichte und Sozialgeschichte», en Vergangene Zukunft: Zur Semantik geschichtlicher Zeiten. Frankfurt am Main: Suhrkamp.

Kramer, Matthew H. 2007. Objectivity and the rule of law. Nueva York: Cambridge University Press.

Lauth, Hans-Joachim y Jenniver Sehring. 2009. «Putting deficient Rechtsstaat on the research agenda: reflections on diminished subtypes», Comparative Sociology, (8): 165-201. Disponible en: https://doi.org/10.1163/156913309X421637.

Lauth, Hans-Joachim. 2004. Demokratie und Demokratiemessung: eine konzeptionelle Grundlegung für den interkulturellen Vergleich. Heidelberg: Verlag für Sozialwissenschaften. Disponible en: https://doi.org/10.1007/978-3-663-01617-5.

Levitsky, Steven y James Loxton. 2013. «Populism and competitive authoritarianism in the Andes», Democratization, 20 (1): 107-136. Disponible en: https://doi.org/ 10.1080/13510347.2013.738864.

Levitsky, Steven y Lucan Way. 2010. Competitive authoritarianism: hybrid regimes after the Cold War. Nueva York: Cambridge University Press. Disponible en: https://doi.org/10.1017/CBO9780511781353.

Madrid, Raúl, Wendy Hunter y Kurt Weyland. 2010. «The policies and performance of the contestatory and moderate left», en K. Weyland et al. (coords.), Leftist governments in Latin America: successes and shortcomings. Nueva York: Cambridge University Press. Disponible en: https://doi.org/10.1017/CBO9780511778742.007.

Mainwaring, Scott, Daniel Brinks y Aníbal Pérez-Liñán. 2007. «Classifiying political regimes in Latin America, 1945-2004», en G. Munck (coord.), Regimes and democracy in Latin America: Theories and methods. Oxford: Oxford University Press.

Majone, Giandomenico. 1994. Independence vs. accountability?: non-majoritarian institutions and democratic government in Europe. EUI working paper, no. 94/3. Florencia: European University Institute.

Martínez, Rubén. 2010. «El nuevo diseño institucional ecuatoriano. Democracia, funciones y legitimidad en la constitución ecuatoriana de 2008», en J. Cabezas y C. Parreño (coords.), Diseño Democratico. Quito: IDEA International.

Maturana, Humberto. 2002. "Autopoiesis, structural coupling and cognition: A history of these and other notions in the biology of cognition", Cybernetics and Human Knowing, 9 (3/4): 5-34.

Maurer, Hartmut. 2010. Staatsrecht I : Grundlagen, Verfassungsorgane, Staatsfunktionen. Munich: Beck.

Mayorga, René Antonio. 2010. Populismo radical y desmontaje de la democracia: el camino hacia la dictadura plebiscitaria [inédito].

Mazzuca, Sebastián. 2010. "Access to power versus exercise of power. Reconceptualizing the quality of democracy in Latin America", Studies in Comparative International Development, 45: 334-357. Disponible en: https://doi.org/10.1007/ s12116-010-9069-5.

Mejía, Andrés. 2011. «Revolución o delegación ciudadana? Democracia, gobierno y rendición de cuentas en Ecuador.», en G. O’Donnell et al. (coords.), Democracia Delegativa. Buenos Aires: Prometeo Libros. 
Møller, Jørgen y Svend-Erik Skaaning. 2014. The rule of law: definitions, measures, patterns and causes. Basingstoke: Palgrave Macmillan. Disponible en: https://doi. org/10.1057/9781137320612.

Montúfar, César. 2010. «Democracia versus aclamación plebiscitaria. El nuevo modelo constitucional ecuatoriano», en J. Cabezas y C. Parreño (coords.), Diseño Democratico. Quito: IDEA International.

Mota, Aurea. 2017. «O constitucionalismo democrático latino-americano em perspectiva históric», en L. Avritzer et al. (coords.), O constitucionalismo democrático latino-americano em debate: Soberania, separação de poderes e sistema de direitos. Belo Horizonte: Autêntica Editora.

Munck, Gerardo. 2007. "The study of politics and democracy: touchstones of a research agenda", en G. Munck (coord.), Regimes and democracy in Latin America: Theories and methods. Oxford: Oxford University Press.

Munck, Gerardo. 2010. Comparative Politics-Taking stock and looking forward. Commitee on Concepts and Methods-Working Paper Series. México DF: Centro de Investigación y Docencia

Nolte, Detlef y Almut Schilling-Vacaflor. 2012. "Introduction: The times they are a changin': Constitutional transformation in Latin America since the 1990s», en D. Nolte y A. Schilling-Vacaflor (coords.), New Constitutionalism in Latin America. Promises and practices. Farnham: Ashgate. Disponible en: https://doi.org/10.1080 /1351847X.2012.723281.

O’Donnell, Guillermo. 2001. "Democracy, law, and comparative politics», Studies in Comparative International Development, 36 (1): 7-36. Disponible en: https://doi. org/10.1007/BF02687583.

O’Donnell, Guillermo. 2003. «Horizontal accountability: The legal institutionalization of mistrust», en S. Mainwaring y C. Welna (coords.), Democratic accountability in Latin America. Oxford: Oxford University Press. Disponible en: https://doi. org/10.1093/0199256373.003.0002.

O’Donnell, Guillermo. 2011. «Nuevas reflexiones acerca de la democracia delegativa», en G. O’Donnell et al. (coords.), Democracia Delegativa. Buenos Aires: Prometeo Libros.

Poulantzas, Nicos. 1968. Pouvoir politique et classes sociales. Paris: F. Maspero.

Quiroga, Hugo. 2011. "Parecidos de familia. La democracia delegativa y el decisionismo democrático», en G. O’Donnell et al. (coords.), Democracia Delegativa. Buenos Aires: Prometeo Libros.

Rosanvallon, Pierre. 2008. La légitimité démocratique: impartialité, réflexivité, proximité. París: Seuil.

Salazar, Pedro. 2013. Politica y derecho. Derechos y garantías: cinco ensayos latinoamericanos. Mexico DF: Editorial Fontamara.

Sartori, Giovanni. 1995. Teoría de la democracia. 1, El debate contemporáneo. Madrid: Alianza Editorial.

Schedler, Andreas. 2011. «International Encyclopedia of political Science», en B. Badie y D. Berg-Schlosser (coords.), Concept formation. Thousand Oaks: SAGE. 
Schmitt, Carl. 1996. Der Hüter der Verfassung. Berlín: Duncker und Humblot. Disponible en: https://doi.org/10.3790/978-3-428-48743-1.

Sejersted, Francis. 1988. «Democracy and the rule of law: some historical experiences of contradictions in the striving for good government», en J. Elster y R. Slagstad (coords.), Constitutionalism and democracy. Cambridge: Cambridge University Press. Disponible en: https://doi.org/10.1017/CBO9781139173629.006.

Stern, Klaus. 1984. Das Staatsrecht der BRD Band I/2. München: C.H. Beck.

Striker, Gisela. 1990. "Ataraxia: Happiness as Tranquility», The Monist, 73 (1): 97-110. Disponible en: https://doi.org/10.5840/monist199073121.

Sunstein, Cass R. 1988. "Constitutions and democracies: an epilogue», en J. Elster y R. Slagstad (coords.), Constitutionalism and democracy. Cambridge: Cambridge University Press. Disponible en: https://doi.org/10.1017/CBO9781139173629.012.

Thatcher, Mark y Alec Sweet. 2002. «Theory and practice of delegation to non-majoritarian institutions», West European Politics, 25 (1): 1-22. Disponible en: https:// doi.org/10.1080/713601583.

Thatcher, Mark. 2005. The third force?: Independent regulatory agencies and elected politicians in Europe. Londres: School of Public Policy, University College London.

Unger, Sebastian. 2008. Das Verfassungsprinzip der Demokratie. Tübingen: Mohr Siebeck.

Vibert, Frank. 2007. The rise of the unelected: democracy and the new separation of powers. Cambridge: Cambridge University Press. Disponible en: https://doi. org/10.1017/CBO9780511491160.

Viciano, Roberto y Rubén Martínez. 2010. «Los procesos constituyentes latinoamericanos y el nuevo paradigma constitutional», Revista Del Instituto de Ciencias Juridicas de Puebla, 4 (25): 7-29.

Viciano, Roberto y Ruben Martínez. 2011. «El nuevo constitucionalismo latinoamericano: fundamentos para una construcción doctrinal», Revista General de Derecho Público Comparado, (9): 1-24.

Vidotte, María Cristina y Freitas Vitor Sousa. 2017. «Novo constitucionalismo democrático latino-americano: paradigma jurídico emergente em tempos de crise paradigmática», en L. Avritzer et al. (coords.), O constitucionalismo democrático latino-americano em debate: Soberania, separação de poderes e sistema de direitos. Belo Horizonte: Autêntica Editora.

Weber, Max. 2005. Wirtschaft und Gesellschaft. Berlín: Zweitausendeins.

Wolff, Heinrich A. 1998. Das Verhältnis von Rechtsstaats- und Demokratieprinzip: Antrittsvorlesung im Wintersemester 1998/99, Speyer, den 16. Dezember 1998. Speyer: Dt. Hochschule für Verwaltungswissenschaften.

Wolff, Jonas. 2008. «Bolivien nach der Constituyente: Auseinandersetzungen in und um Demokratie», Lateinamerika Analysen, 7 (2): 165-180.

Wolff, Jonas. 2010. «Postneoliberal verfasst? Ein vergleichender Blick auf die neuen Verfassungen in Bolivien und Ecuador», Kritische Justiz, 43 (4): 407-415. Disponible en: https://doi.org/10.5771/0023-4834-2010-4-407. 
Wolff, Jonas. 2013. «Towards a post-liberal democracy in Latin America? A conceptual framework applied to Bolivia», Journal of Latin American Studies, (45): 31-59. Disponible en: https://doi.org/10.1017/S0022216X12000843.

Wolkmer, Antonio y Lucas Machado. 2011. «Tendências contemporâneas do constitucionalismo latino-americano: estado plurinacional e pluralismo jurídico", Pensar Fortaleza, 16 (2): 371-408. Disponible en: http://dx.doi.org/10.5020/23172150.2012.371-408.

Presentado para evaluación: 4 de agosto de 2017.

Aceptado para publicación: 30 de abril de 2018.

\section{FRANZ BARRIOS-SUVELZA}

franzbarrios@yahoo.com

Doctor en Planificación Urbana por la Universidad Técnica de Berlin y docente de la Facultad de Ciencias del Estado en la Universidad de Erfurt (Alemania). Sus líneas de investigación son: Estado de derecho, democracia, constitucionalismo, descentralización y federalismo. 